\title{
POLÍTICA DE FORMAÇÃO DOCENTE NO CONTEXTO DO PROEJA: REALIDADE E PERSPECTIVAS
}

\section{POLÍTICA DE FORMACIÓN DE PROFESORES EN EL CONTEXTO DEL 'PROEJA': REALIDAD Y PERSPECTIVAS}

\author{
TEACHER TRAINING POLICY IN 'PROEJA' CONTEXT: REALITY AND \\ PERSPECTIVES
}

\author{
Sebastião Silva SOARES ${ }^{1}$ \\ Catia Piccolo Viero DEVECHI ${ }^{2}$
}

RESUMO: Historicamente, a formação de professores no campo das políticas públicas no país tem sido desenvolvida em contextos diversos, articulada aos interesses políticos e relações de poder, demarcando, na maioria das vezes, ações formativas docente numa perspectiva técnica e mercadológica. Diante disso, o artigo analisa as possibilidades e os desafios encontrados na implementação da política de formação docente para o Programa Nacional de Integração da Educação Profissional com a Educação Básica na Modalidade de Educação de Jovens e Adultos (Proeja). Por meio da abordagem hermenêutica crítica e reconstrutiva, busca-se compreender a percepção dos professores atuantes em relação ao programa, utilizando entrevistas e questionários. Os resultados da pesquisa apontam para o desconhecimento dos objetivos do programa e da política decorrente da falta de oportunidade em participar do processo formativo, que se soma com questões pessoais e profissionais. Concluímos que a proposta de formação docente para o Proeja é, ainda, uma realidade distante na instituição pesquisada, demandando o amadurecimento político e pedagógico.

PALAVRAS-CHAVE: Política de formação docente. Educação profissional. Proeja.

RESUMEN: Históricamente la formación docente en el campo de las políticas públicas en el país se ha desarrollado en diversos contextos articulados con intereses políticos y relaciones de poder, delimitando, la mayoría de las veces, las acciones de capacitación docente desde una perspectiva técnica y de mercado. El artículo analiza las posibilidades y los desafíos encontrados en la implementación de la política de formación docente para el Programa Nacional para la Integración de la Educación Vocacional con la Educación Básica en la Modalidad de Educación de Jóvenes y Adultos (Proeja). A través del enfoque hermenéutico crítico y reconstructivo, se busca comprender la percepción de los docentes actuantes acerca del programa, utilizando entrevistas y cuestionarios. Los resultados de la investigación apuntan a la falta de conocimiento de los objetivos del programa y la política resultante de la falta de oportunidades para participar en el proceso de capacitación que se suma a los problemas personales y profesionales. Llegamos a la conclusión de que la propuesta de

${ }^{1}$ Universidade Federal do Tocantins (UFT), Arraias - TO - Brasil. Professor. ORCID: https://orcid.org/00000002-5572-014X. E-mail: sebastiaokenndy@yahoo.com.br

${ }^{2}$ Universidade de Brasília (UnB), Brasília - DF - Brasil. Professora. ORCID: https://orcid.org/0000-0002-51471609. E-mail: catiaviero@gmail.com 
formación docente para Proeja sigue siendo una realidad lejana en la institución investigada, que exige una maduración política y pedagógica.

PALABRAS CLAVE: Política de formación docente. Educación profesional. Proeja.

ABSTRACT: Historically teacher education in the field of public policies in the country has been developed in diverse contexts articulated with political interests and power relations, demarcating, most of the time, teacher training actions from a technical and market perspective.The article discusses the possibilities and challenges encountered in the implementation of the teacher education policy for the National Program for the Integration of Vocational Education with Basic Education in the Youth and Adult Education Modality (Proeja). Through the critical and reconstructive hermeneutic approach, it seeks to understand teachers' perception of the program, using interviews and questionnaires. The research's results point to the lack of knowledge about the program objectives and the policy resulting from the lack of opportunity to participate in the training process, besides personal and professional issues. We conclude that the proposal of teacher education for Proeja is still a distant reality in the researched institution, demanding political and pedagogical maturation.

KEYWORDS: Teacher training policy. Professional education. Proeja.

\section{Introdução}

A política de formação docente para os professores atuantes no contexto da Educação de Jovens e Adultos (EJA) é primordial na promoção social da EJA como direito social e modalidade educacional no Brasil. Trata-se de uma preocupação atual, particularmente devido à expansão da Rede Federal de Educação Profissional e Tecnológica no país. O Programa Nacional de Integração da Educação Profissional com a Educação Básica na Modalidade de Educação de Jovens e Adultos (Proeja), criado em 2005 (BRASIL, 2005), foi uma das ações do governo federal implementadas para garantir a educação da população de jovens e de adultos que vivenciam o processo de marginalização do sistema, principalmente quando abandonam os estudos para complementar a renda familiar nos primeiros anos da escolarização do Ensino Fundamental.

Este artigo busca discutir o desenvolvimento do Proeja utilizando os resultados de uma pesquisa desenvolvida no Instituto Federal de Educação, Ciência e Tecnologia de Goiás (IFG), cujo objetivo foi compreender as possibilidades e os desafios na implementação da política de formação docente para o Proeja, conforme a percepção dos professores atuantes no programa. Na pesquisa, foi aplicado um questionário a 20 docentes atuantes no curso de 
Técnico em Manutenção e Suporte para Internet, integrado ao ensino médio, na modalidade EJA do IFG, além de entrevistas semiestruturadas com três de seus professores.

\section{Antecedentes históricos do Proeja}

Antes de adentramos na reflexão sobre o Proeja, precisamos rememorar alguns aspectos históricos anteriores à implantação do programa no Brasil. Com o Decreto n. 2.208 (BRASIL, 1997), a educação profissional passou por uma nova configuração, a qual pode ser desenvolvida de forma independente do ensino regular ou em modalidades que contemplem as estratégias de educação continuada. Segundo o $4^{\circ}$ parágrafo do Decreto n. 2.208 (BRASIL, 1997), a educação profissional é uma "modalidade de educação não formal e duração variável, destinada a proporcionar ao cidadão trabalhador conhecimentos que lhe permitam reprofissionalizar-se".

Para Ferreira (2012), tal compreensão da educação profissional traz uma visão simplificada de educação, que prioriza basicamente o treinamento ou capacitação para atender às novas configurações do mundo do trabalho. Frigotto, Ciavatta e Ramos (2012) discorrem que, com o Decreto n. 2.208 (BRASIL, 1997) e outros instrumentos legais, a política educacional perdeu a garantia de uma proposta de educação integrada, sob os princípios humanísticos e científico-tecnológicos, defendidos pela Lei de Diretrizes e Base da Educação Nacional (LDB/1996) - Lei n. 9.394 (BRASIL, 1996). Seguiu-se, porquanto, uma formação fragmentada e aligeirada para atender quase que exclusivamente aos imperativos do desenvolvimento econômico no país.

Para Ferreira (2012), houve por meio do Decreto n. 2.208 (BRASIL, 1997) uma redução da oferta de vagas de formação técnica nas escolas públicas e a ampliação no setor privado, o que dificultou o acesso de jovens à modalidade de ensino. A educação profissional desvinculada da formação básica deixou em segundo plano a relação entre a educação escolar, o trabalho e as práticas sociais. Segundo Kuenzer (2000, p.28), o dualismo entre a formação geral e a formação técnica "legitima a existência de dois caminhos bem diferenciados a partir das funções essenciais do mundo da produção econômica e para o ensino médio e profissional" (KUENZER, 2000, p. 28). Propondo que a educação profissional seja desvinculada da formação básica, o Decreto demonstra que a formação geral/propedêutica não seria suficiente para oferecer a preparação do jovem e do adulto para ingressar no mundo do trabalho. 
Por meio da mobilização de diversos setores e agentes (da educação, dos sindicatos e pesquisadores), que reconheceram a importância de integrar a formação técnica com a geral, tal decreto foi revogado e substituído pelo Decreto n. 5.154 (BRASIL, 2004). Assim, a educação profissional já prevista no art. 39 da LDB/1996 (BRASIL, 1996) passaria, segundo o novo Decreto, a ser viabilizada por meio de cursos, programas de formação inicial e continuada de trabalhadores, educação profissional técnica de nível médio, educação profissional tecnológica de graduação e de pós-graduação.

Os Cursos e programas poderiam ser oferecidos de maneira integrada para os concluintes do Ensino Fundamental; concomitantemente, para os alunos que já concluíram o Ensino Fundamental ou que estivessem em processo de formação no nível médio; e, na modalidade subsequente, para os concluintes do Ensino Médio (BRASIL, 2004). Eles deveriam, preferencialmente, estar articulados com a EJA, com vistas à qualificação para o trabalho e à elevação do nível de escolaridade do trabalhador. Ao analisarmos as diretrizes do Decreto n. 5.154 (BRASIL, 2004), em comparação com o Decreto n. 2.208 (BRASIL, 1997), percebemos concepções acerca da educação profissional, como a ampliação de conceitos e formas de acesso. Além disso, passou-se a reconhecer o aluno-trabalhador como um sujeito de saberes e experiências que devem ser integralmente levadas em conta no processo de formação. Buscaremos aprofundar essa análise no tópico subsequente, que se refere à criação do Proeja como uma proposta de formação integral.

\section{O Proeja: elementos conceituais e estruturais do programa}

O Proeja se origina do Decreto n. 5.478, de 24 de junho de 2005 (BRASIL, 2005). Com isso, foi denominado, inicialmente, como Programa de Integração da Educação Profissional ao Ensino Médio na modalidade Educação de Jovens e Adultos. Ele expôs a decisão governamental de atender à demanda de jovens e adultos "pela oferta de educação profissional técnica de nível médio, da qual, em geral, são excluídos, bem como, em muitas situações, do próprio ensino médio" (BRASIL, 2007, p. 12). Com o questionamento de um grupo de pesquisadores, profissionais do ensino e agentes de movimentos sociais, passou-se a questionar o programa, ao propor a ampliação em termos de abrangência e aprofundamento de princípios epistemológicos (FRIGOTTO; CIAVATTA; RAMOS, 2012). Isso fez com que o Decreto n. 5.478 (BRASIL, 2005) fosse revogado para a promulgação do Decreto n. 5.840 (BRASIL, 2006), pelo qual se tornou Programa de Integração da Educação Profissional com a Educação Básica na modalidade de Educação de Jovens e Adultos (Proeja). 
De fato, tais iniciativas levaram a várias mudanças no programa, como o nível de ensino para o ingresso, com a inclusão do ensino fundamental e a ampliação das instituições de ensino que poderiam ofertar cursos vinculados ao Proeja. Segundo Ciavatta (2012, p. 81), a mudança advinda da legislação desse programa "tentou possibilitar a organização de itinerários formativos, bem como a certificação de conhecimentos construídos pelos trabalhadores em processos formativos". Para a autora, a construção metodológica do programa, como a certificação dos alunos e as etapas dos cursos com a respectiva terminalidade, possibilitou ao trabalhador uma nova oportunidade para desenvolver o processo de escolarização geral e específica de maneira integrada, apesar de existir uma dicotomia entre a formação geral e específica para certificar a qualificação voltada ao trabalho, no que tange às diretrizes do Proeja (CIAVATTA, 2012).

Segundo Machado (2006), o Proeja se estabelece e ganha significação em um contexto de mudança paradigmática e de busca de universalização da educação básica, de ampliação das oportunidades de qualificação profissional e de perspectivas de continuidade de estudos em nível superior para um público portador de escolaridade interrompida, o que limita sobremaneira as chances de melhor inserção na vida social e no mundo do trabalho. Moura (2006, p. 62) diz que "o Proeja surge com a dupla finalidade de enfrentar as descontinuidades que marcam a modalidade EJA no Brasil”, no âmbito do Ensino Médio, além de integrar a educação básica a uma formação profissional que contribua para a integração socioeconômica desses coletivos. Já para Oliveira e Machado (2012), o Proeja possibilitou, pela primeira vez na história da EJA, a oferta de uma formação de nível médio integrada com a educação profissional, o que contribuiu para ampliar os conceitos da EJA até então relacionados à alfabetização e ao Ensino Fundamental. Diante disso, ao articularmos as ideias do Decreto n. 2.208 (BRASIL, 1997) com a criação do Decreto n. 5.154 (BRASIL, 2004), percebemos que tais legislações foram primordiais para a construção do Proeja, sendo as lacunas preenchidas com a promulgação do Decreto n. 5.840 (BRASIL, 2006).

A origem do Proeja permeou acontecimentos histórico-sociais do país, especificamente a partir da década de 1990, que apresentaram novos desafios e possibilidades para o desenvolvimento da EJA integrada à educação profissional e tecnológica, em especial, com a participação de agentes públicos e da sociedade na implementação da proposta nas instituições de ensino. 


\section{A formação de professores para o Proeja}

Nos últimos anos, muitas discussões vêm sendo feitas sobre a formação do profissional da escola básica. Diante de diversos entendimentos e movimentos realizados em torno do descontentamento das Diretrizes Nacionais para Formação de Professores da Escola Básica, de 2002, a necessidade de articular o ensino superior e a escola básica, somados às metas do Plano Nacional de Educação - PNE para o decênio de 2014/2024, que buscam a melhoria na formação inicial e continuada de profissionais do magistério da educação básica, a necessidade de se ter uma base comum nacional para a formação inicial e continuada capaz de oferecer sólida formação teórica e interdisciplinar, somada ao compromisso social e valorização do profissional da educação, foi aprovada, em 2015, a Resolução CNE/CP $\mathrm{n}^{\circ} 2$, que instituiu as Diretrizes Curriculares Nacionais para a Formação Inicial em nível superior e para a formação continuada. Tais diretrizes aplicam-se: "à formação de professores para o exercício da docência na educação infantil, no ensino fundamental, no ensino médio e nas respectivas modalidades de educação (Educação de Jovens e Adultos, Educação Especial, Educação Profissional e Tecnológica, Educação do Campo, Educação Escolar Indígena, Educação a Distância e Educação Escolar Quilombola), nas diferentes áreas do conhecimento e com integração entre elas, podendo abranger um campo específico e/ou interdisciplinar". (BRASIL, 2015). A resolução explícita que a formação continuada docente

Deve se dar pela oferta de atividades formativas e cursos de atualização, extensão, aperfeiçoamento, especialização, mestrado e doutorado que agreguem novos saberes e práticas, articulados às políticas e gestão da educação, à área de atuação do profissional e às instituições de educação básica, em suas diferentes etapas e modalidades da educação (BRASIL, $2015, \mathrm{~s} / \mathrm{p})$.

Nesse entremeio, para formação continuada dos professores da escola básica foram oferecidos os seguintes programas: Formação no Pacto Nacional pela Alfabetização na Idade Certa, ProInfantil, Plano Nacional de Formação de Professores da Educação Básica - Parfor, Proinfo Integrado, e-Proinfo, Pró-letramento; Gestar II, Rede Nacional de Formação Continuada de Professores (MEC, 2019) ${ }^{3}$. No que se refere ao Proeja, mais especificamente sobre a educação profissional tecnológica integrada à EJA, foram implementados cursos de segunda graduação para os professores não licenciados, cursos de aperfeiçoamento, pósgraduação lato sensu em educação profissional e tecnológica e a criação do Mestrado Profissional em Educação Tecnológica em Rede Nacional (ProfEPT).

3 Informação obtida em: http://portal.mec.gov.br/component/tags/tag/35753-formacao-continuada-paraprofessores. Acesso: 26 out. 2019. 
Observa-se na Resolução CNE/CP n 2 de 2015 referenciada, uma perspectiva de formação pautada na diversidade, nos direitos humanos e inclusão educacional, em consonância com as estratégias do PNE/2014-2024 (DOURADO, 2015). Aspecto este que corrobora os princípios do Documento Base do Proeja, o qual propõe "uma sólida formação continuada dos docentes, por serem estes também sujeitos da educação de jovens e adultos, em processo de aprender por toda a vida" (BRASIL, 2007, p. 37).

O programa do Proeja tem a formação de professores como ponto estratégico para a concretização dos seus objetivos, em especial "a construção de um quadro de referência e à sistematização de concepções e práticas político-pedagógicas e metodológicas que orientem a continuidade do processo formativo dos jovens e adultos" (BRASIL, 2007, p. 60). Nesse sentido, as instituições proponentes devem contemplar, no plano de trabalho, a formação continuada dos seus docentes por meio de, no mínimo: formação continuada totalizando 120 horas, com uma etapa prévia ao início do projeto de, no mínimo, 40 horas. A Secretaria de Educação Profissional e Tecnológica (SETEC), como gestora nacional do Proeja, é responsável pelo estabelecimento de programas especiais para a formação de formadores e a pesquisa sobre a EJA.

Segundo Moura (2008b), a oferta dos cursos de especialização para o Proeja foi iniciada, em 2006, em 15 instituições da Rede Federal de Educação Profissional e Tecnológica, formando-se cerca de 1.500 profissionais: "Em 2007, abriu-se a segunda fase do programa, ampliando-se para vinte e um o número de instituições ofertantes, estimando formar mais 2.600 professores e gestores" (MOURA, 2008b, p. 116). Entretanto, diante de tal regulamentação, muitos desafios têm surgido no campo da política educacional, visto que a proposição do programa trouxe aspectos inovadores, qualitativos e quantitativos, de amplitude, concepção e localização, para a educação no país” (LIMA FILHO, 2010, p. 114), que exigem formação específica de professores para atuação nos cursos.

Notoriamente, torna-se essencial a formação específica do professor, principalmente pelo fato de o programa apresentar uma nova concepção de currículo integrado, que busca constituir a formação geral com a do jovem e do adulto no espaço escolar. Conforme Ciavatta (2012, p. 84), “a educação geral deve ser parte inseparável da educação profissional em todos os campos onde se dá a preparação para o trabalho, seja como processo produtivo seja como processo educativo".

Brito (2018) diz que falta aos professores e gestores uma maior compreensão sobre o currículo integrado protagonizado pelo Proeja, tanto no âmbito do discurso oficial quanto na implementação por parte da instituição que pesquisou. O currículo integrado no Proeja 
demonstra, apesar de apresentar uma perspectiva inovadora no ensino da educação profissional, limitações na operacionalização e nas ações de formação pedagógica docente (SILVA, 2013).

A organização do currículo integrado no Proeja é pautada pela dimensão do trabalho como princípio educativo, ao promover a inter-relação entre trabalho, ciência, técnica, tecnologia, humanismo e cultura. A proposta do currículo integrado tenciona superar a ideia dual de que, historicamente, o homem vem sofrendo pela divisão social do trabalho entre o fazer e o pensar. Nas palavras de Ciavatta (2005, p. 85), esse processo pretende:

superar a redução da preparação para o trabalho ao seu aspecto operacional simplificado, escoimado dos conhecimentos que estão na sua gênese cientificamente-tecnológica e na sua apropriação histórico-social. Como formação humana, o que se busca é garantir ao adolescente, ao jovem e ao adulto trabalhador o direito a uma formação completa para a leitura do mundo e para a atuação como cidadão permanente a um país, integrado dignamente à sociedade política. Formação que, neste sentido, supõe a compreensão das relações sociais subjacentes a todos os fenômenos.

Assim, a formação pensada sob a perspectiva do currículo integrado não pretende apenas preparar o sujeito para o mercado de trabalho conforme as exigências percebidas atualmente - em especial, com o uso de novas tecnologias nos processos de produção -, como também se volta para uma formação integral que complemente a relação entre teoria e prática, na qual o sujeito pode compreender o seu papel social e buscar a formação humana no sentido pleno.

A priori, o currículo integrado propõe "afirmar a educação como meio pelo qual as pessoas realizam-se como sujeitos históricos que produzem sua existência frente a vivências, produzindo valores, conhecimento e cultura por sua ação educativa” (RAMOS, 2005, p. 123). Nessa perspectiva, a formação do sujeito não será apenas para atender às exigências do sistema econômico, conforme foi tratada a educação na dimensão socio-histórica, mas também para corresponder às necessidades humanas, culturais e sociais. Segundo o documento base do Proeja:

o que se pretende é uma integração epistemológica, de conteúdos, de metodologias e de práticas educativas. Refere-se a uma integração teoriaprática, entre o saber e o saber-fazer. Em relação ao currículo, pode ser traduzido em termos de integração entre uma formação humana mais geral, uma formação para o ensino médio e para a formação profissional (BRASIL, 2007, p. 41).

A proposta do currículo integrado exige que o professor tenha uma "formação que lhe aproxime da problemática das relações entre educação e trabalho e do vasto campo da 
educação profissional" (MOURA, 2008a, p. 32), além das especificidades da EJA. Isso leva, segundo o documento base, a novas culturas escolares e perspectivas de formação do docente.

\section{A percepção dos professores ${ }^{4}$ do Proeja}

No que diz respeito às 14 respostas do questionário, os resultados indicaram que os sujeitos pesquisados têm entre 28 e 38 anos de idade. Quanto ao sexo, dez professores são do sexo masculino, e quatro do sexo feminino. Todos são efetivos na instituição e exercem cargos de Dedicação Exclusiva (DE). No que concerne à formação inicial, há docentes com formação em licenciatura e bacharelado e, sobre a formação em pós-graduação, constatamos especialistas, mestres e doutores geralmente relacionados à área de formação inicial.

Em relação ao tempo de serviço na instituição, grande parte dos pesquisados estava à época da pesquisa no período do estágio probatório. Quanto à docência, a maioria tem um tempo significativo de atuação na área profissional de formação. No entanto, a maior parte do corpo docente não possui experiência com os alunos da EJA, salvo em alguns casos, nos quais são narradas experiências com esse público. Esse dado foi ressaltado também por Morais (2015), em uma pesquisa sobre professores atuantes no Proeja, em particular, à falta de experiência profissional docente dos professores que atuavam no curso Técnico em Cozinha no programa.

Outro ponto de análise da nossa pesquisa foi a formação para atuar no Proeja, visto que um número considerável de respondentes, até os que apresentaram experiências na EJA, não havia realizado nenhuma formação para atuar em tal modalidade da educação. Notamos a ausência de formação pedagógica por parte dos professores, em se tratando da atuação na EJA, além das consequências dessa falta do conhecimento pedagógico e didático, levando o docente a ser o gestor da própria formação a fim de garantir os objetivos propostos pela instituição.

Quando direcionamos essa provocação aos profissionais bacharéis, foi nítida a falta de formação pedagógica. Santos (2016, p. 81) afirma como processo emergencial a formação pedagógica para os professores atuantes no programa do Proeja, pois os docentes pesquisados mencionaram a importância e o papel didático de possuírem uma formação pedagógica para atuar no contexto da educação de jovens e adultos. Os colaboradores ressaltaram que a prática e os saberes docentes são mobilizados ao ingressarem na instituição, "tendo, como parâmetro, os bons professores que tiveram ao longo da trajetória escolar".

\footnotetext{
${ }^{4}$ Os professores receberam nomes fictícios no estudo, compostos por elementos alfanuméricos.
} 
Assim como na pesquisa mencionada, Guedes e Sanchez (2017) observaram que os saberes profissionais dos professores bacharéis atuantes na educação profissional são provenientes de experiências de empresas, gerenciamento de obras, comércio, laboratórios, dentre outras, e não especificamente da docência como profissão. Evidencia-se, assim, que a formação para os professores atuantes na educação profissional, em particular os docentes na modalidade EJA, deve priorizar as especificidades dessa modalidade de ensino, além de reconhecer as dimensões socioculturais e formativas de alunos e professores. Em continuação, questionamos os professores sobre o fato de estarem preparados para ministrar aulas no Proeja - nove docentes afirmaram que sim, e cinco responderam que não.

Os dados demonstram que a maioria dos entrevistados se sente preparada para trabalhar com os jovens e adultos do programa, apesar das limitações encontradas na formação docente. Entretanto, uma parcela mínima não se sente apta para se inserir no Proeja, demonstrando, mais uma vez, as fragilidades da formação inicial e continuada, pois "para ensinar o professor necessita de conhecimentos e práticas que ultrapassam o campo de sua especialidade” (PIMENTA; ANASTASIOU, 2005, p. 16).

Paralelamente a isso, os professores demonstraram também pouco conhecimento acerca das propostas de formação docente para o Proeja, visto que os cursos ocorrem na instituição sem que todos tenham acesso, dilema apreendido por Ribeiro (2012) na sua pesquisa, quando observou pouca participação dos professores nas ações formativas direcionadas aos docentes atuantes no Proeja, principalmente por apresentarem nas trajetórias profissionais mestrado e doutorado, além da falta de interesse para atuar na modalidade da EJA.

Por outro lado, os docentes que já participaram ou participam de algum curso afirmaram, na nossa pesquisa, que os formadores dos cursos não apresentam experiência específica para trabalhar questões relativas ao programa. Para muitos docentes, os cursos ofertados não atendem às necessidades básicas atinentes à prática pedagógica com os alunos em sala de aula, como demonstram estas afirmativas:

Não conheço a política de formação docente, mas acredito na sua necessidade para a formação de um quadro docente comprometido com as particularidades da EJA (P3F).

Embora eu afirme que conheça, o que eu sei é de leituras de documentos disponibilizados pelo MEC e de trocas de informações entre docentes. Não é nada elaborado (P12M). 
Penso que a política de formação para o Proeja se dá (e se deu) de forma pontual e que os cursos de especialização, em muitos lugares, se deram de forma superficial e instrumental (P14F).

No percurso da entrevista, os docentes foram unânimes também ao afirmar que as iniciativas formativas ocorrem de modo esporádico na instituição. No entanto, sobressaiu o fato de os professores não saberem que há, na proposta do programa, ações que visem à formação docente, como podemos observar nestes excertos:

A instituição disponibilizou um curso de capacitação em Proeja, mas, do jeito que foi conduzido, não envolveu de maneira satisfatória todos os docentes $(P 2 F)$.

Acredito que tem sido feito muito pouco, e os gestores não estão preocupados em fornecer complementação à formação dos professores. Estão preocupados apenas se as aulas estão sendo dadas ou não (P6M).

Ainda não está evidente uma mobilização efetiva para a formação docente, pois ainda não há uma política estabelecida na instituição em que atuo $(P 3 F)$.

Para muitos professores, cursos e capacitações desenvolvidos pela instituição eram propostos em consonância com dilemas vivenciados por eles. Afirmaram que os conhecimentos sobre o programa decorrem do estudo para ingressar na instituição por meio de concurso público. Não encontramos, de maneira ampla, discussões sobre as formações recebidas pelos docentes para atuarem no Proeja, devido à limitação para participar de tais cursos, seja pela falta de informações ou de oportunidades de acesso, resultado que vai ao encontro dos estudos de Moraes (2015) e Brito (2017).

Em outro aspecto, os docentes ressaltaram a importância de questões da EJA/Proeja serem debatidas nas diretrizes dos cursos de formação docente ${ }^{5}$ para oferecer, aos futuros professores e àqueles que estão em serviço, conhecimentos e metodologias voltadas às práticas pedagógicas, de acordo com as necessidades de ensino e de aprendizagem exigidas para o público-alvo do programa. Tais aspectos são retratados nos excertos a seguir:

Acho que os cursos de licenciatura deveriam incluir nas práticas pedagógicas atividades que ajudem a entender o que são os cursos EJA $e$ Proeja para que os professores possam chegar à sala de aula preparados para compreender as especificidades do público e pautar seu planejamento de aulas e avaliações, levando em conta tais especificidades (P6M).

5 Em 2018/01, a Instituição implantou, por meio de uma iniciativa entre o Ministério da Educação e a Universidade Aberta do Brasil (UAB), um sistema de rede, o Curso de Formação Pedagógica para Graduados não licenciados, visando à formação de profissionais para atuação na educação profissional e tecnológica na Educação Básica e Ensino Superior Tecnológico. 
Ainda está em fase muito inicial e não percebo a valorização do Proeja dentro dos institutos. No meu entendimento, ainda há uma marginalização nas políticas institucionais voltadas para o Proeja (P3F).

Nesse sentido, pelos excertos dos professores foi possível identificar lacunas no que tange à formação docente para o Proeja, seja pela falta de construção de espaços em cursos ou nas instituições de ensino nas quais os profissionais atuam, como a falta de compreensão sobre o programa e sua operacionalização, além das dificuldades na organização do processo de ensino-aprendizagem dos alunos do Proeja. Há, portanto, a necessidade de adequação curricular dos cursos de licenciaturas a fim de atender a uma realidade escolar que perpassa a inserção de jovens e de adultos na modalidade EJA e Proeja, pois, na breve história da educação de jovens e adultos analisada, evidenciamos aspectos de omissão, ausência e falta de participação direta do governo na consolidação de uma educação para esses sujeitos sociais.

Constatamos, portanto, que a política de formação docente voltada ao Proeja vem sendo desenvolvida de maneira particular na instituição. Os dados apontam a necessidade de valorizar ações pedagógicas orientadas a uma aprendizagem comunicativa (HABERMAS, 2012) para chegar a acertos mais adequados diante da realidade do Proeja, principalmente no campo da socialização e espaços de vivências. Nesse prisma, a formação dos professores poderia ser construída em uma dimensão coletiva, por meio de acordos, rompendo, assim, com o individualismo e a relação monológica presentes na maioria das propostas de formação, essencialmente no que concerne às estruturas institucionais, formativas e curriculares.

\section{Considerações finais}

Ao retomar a questão norteadora do estudo, que objetivou compreender as possibilidades e os desafios na implementação da política de formação docente para o Proeja, ficou evidenciado que a falta de uma formação pedagógica específica dos professores atuantes no programa impacta diretamente no processo de aprendizagem dos alunos, seja como elemento de emancipação, seja como mecanismo de evasão escolar. Percebemos que não existe um entendimento adequado dos participantes em relação à formação pedagógica do professor para lidar com as especificidades do público da EJA. Notamos, ainda, um distanciamento dos profissionais docentes para atuar nessa modalidade de ensino no contexto da educação profissional e tecnológica.

Nesse sentido, embora a política do Proeja estabeleça diretrizes para a formação dos profissionais que atuam no programa, constatamos certa ausência de engajamento da 
Instituição na sua promoção, fato último que reafirma a necessidade de articulação entre os inseridos no processo de ensino e aprendizagem, além do envolvimento de movimentos sociais e sociedade civil, fortalecendo a EJA como política pública educacional. Não existem, assim, ações suficientes para a participação dos docentes nas tomadas de decisões a fim de atender as necessidades pedagógicas de professores e estudantes.

Os dados rementem à necessidade de compreender a formação docente como ação permanente e contextual, que envolva a participação dos professores, não como meros espectadores e reprodutores de políticas, mas protagonistas da ação formativa. Entendemos que as políticas pensadas e organizadas coletivamente pelos sujeitos envolvidos podem potencializar a meta do programa, possibilitando a construção de espaços formativos mais adequados à realidade dos sujeitos.

\section{REFERÊNCIAS}

BRASIL. Conselho Nacional de Educação. Define as Diretrizes Curriculares Nacionais para a formação inicial em nível superior (cursos de licenciatura, cursos de formação pedagógica para graduados e cursos de segunda licenciatura) e para a formação continuada. Resolução CNE/CP n. 02/2015, de $1^{\circ}$ de julho de 2015. Diário Oficial da União, Brasília, 2 jun. 2015. (Impresso).

BRASIL. Decreto n. 2.208, de 17 de abril de 1997. Regulamenta o $\S 2^{\circ}$ do art. 36 e os arts. 39 a 42 da Lei n. 9.394, de 20 de dezembro de 1996, que estabelece as diretrizes e bases da educação nacional. Diário Oficial da União, Brasília, 18 abr. 1997. Disponível em: http://www.planalto.gov.br/ccivil_03/decreto/D2208.htm. Acesso em: 20 maio 2019.

BRASIL. Decreto n. 5.154, de 23 de julho de 2004. Regulamenta o $\S 2^{\circ}$ do art. 36 e os arts. 39 a 41 da Lei n. 9.394, de 20 de dezembro de 1996, que estabelece as diretrizes e bases da educação nacional, e dá outras providências. Diário Oficial da União, Brasília, 26 jul. 2004. Disponível em: http://www.planalto.gov.br/ccivil_03/_ato20042006/2004/decreto/d5154.htm. Acesso em: 20 maio 2019.

BRASIL. Decreto n. 5.478, de 24 de junho de 2005. Institui, no âmbito das instituições federais de educação tecnológica, o Programa de Integração da Educação Profissional ao Ensino Médio na Modalidade de Educação de Jovens e Adultos - Proeja. Diário Oficial da União, Brasília, 27 jul. 2005. Disponível em: http://www.planalto.gov.br/ccivil_03/_ato20042006/2005/Decreto/D5478.htm. Acesso em: 20 maio 2019.

BRASIL. Decreto n. 5.840, de 13 de julho de 2006. Institui, no âmbito federal, o Programa Nacional de Integração da Educação Profissional com a Educação Básica na Modalidade de Educação de Jovens e Adultos - Proeja, e dá outras providências. Diário Oficial da União, Brasília, 14 jul. 2006. Disponível em: http://www.planalto.gov.br/ccivil_03/_ato20042006/2006/decreto/d5840.htm. Acesso em: 20 maio 2019. 
BRASIL. Lei n. 9.394, de 20 de dezembro de 1996. Estabelece as diretrizes e bases da educação nacional. Diário Oficial da União, Brasília, 23 dez. 1996. Disponível em: http://www.planalto.gov.br/ccivil_03/leis/19394.htm. Acesso em: 20 maio 2019.

BRASIL. Ministério de Educação. Documento base do Proeja. Brasília: MEC, 2007.

BRITO, R. G.; PALAFOX, G. H. M. Entre o prescrito e o vivido: o proeja no Instituto Federal de Educação, Ciência e Tecnologia de Goiás - Campus de Formosa (2010-2015). Revista Pedagógica, Chapecó, v. 20, n. 45, p. 162-181, set./dez. Disponível em: http://bell.unochapeco.edu.br/revistas/index.php/pedagogica/article/view/3933. Acesso em: 20 maio 2019. DOI: http://dx.doi.org/10.22196/rp.v20i45.3933.

CASTRO, E. Currículo integrado do proeja: concepção e implementação no IFMA. Orientadora: Lélia Cristina Silveira de Moraes 2017. 226 f. Dissertação (Mestrado em Educação) - Universidade Federal do Maranhão, São Luís, 2017. Disponível em: https://tedebc.ufma.br/jspui/handle/tede/tede/2112. Acesso em: fev 2020.

CIAVATTA, M. A formação integrada: a escola e o trabalho como lugares de memória e de identidade. In: FRIGOTTO, G.; CIAVATTA, M.; RAMOS, M. (Orgs.). Ensino médio integrado: concepção e contradições. São Paulo: Cortez, 2005.

CIAVATTA, M. Educação Básica e Educação Profissional: descompassos e sintonia necessária. In: OLIVEIRA, E. C.; PINTO, A. H.; FERREIRA, M. J. R. (Orgs.). EJA e educação profissional: desafios da pesquisa e da formação no Proeja. Brasília: Liber Livros, 2012.

DOURADO, L. F. Diretrizes curriculares nacionais para a formação inicial e continuada dos profissionais do magistério da Educação Básica: concepções e desafios. Educação \& Sociedade, v. 36, n. 131, p. 299-324, abr./jun. 2015. Disponível em:

http://www.scielo.br/scielo.php?pid=S010173302015000200299\&script=sci_abstract\&tlng=pt. Acesso em: fev. 2020. DOI: https://doi.org/10.1590/ES0101-73302015151909

FERREIRA, E. B. Do Proeja à formação integrada: limites, avanços e possibilidades de implantação. In: OLIVEIRA, E. C.; PINTO, A. H.; FERREIRA, M. J. R. (Orgs.). EJA e educação profissional: desafios da pesquisa e da formação no Proeja. Brasília: Liber Livros, 2012.

FREIRE, P. Pedagogia da autonomia: saberes necessários à prática educativa. São Paulo: Paz e Terra, 2012.

FRIGOTTO, G.; CIAVATTA, M.; RAMOS, M. A gênese do Decreto n. 5.154/2004: um debate no contexto controverso da democracia restrita. In: FRIGOTTO, G.; CIAVATTA, M.; RAMOS, M. (Orgs.). Ensino médio integrado: concepção e contradições. São Paulo: Cortez, 2012.

GATTI, B. A. Formação de professores no Brasil: características e problemas. Educação \& Sociedade, Campinas, v. 31, n. 113, p. 1355-1379, out./dez. 2010. Disponível em: http://www.scielo.br/scielo.php?script=sci_arttext\&pid=S0101- 
73302010000400016\&lng=pt\&tlng=pt. Acesso em: jan 2020. DOI:

https://doi.org/10.1590/S0101-73302010000400016

GUEDES, I. A. C; SANCHEZ. L. B. A formação docente para a educação profissional técnica e sua influência na atuação dos professores do Instituto Federal do Amapá - Campus Macapá: um estudo de caso. Holos, v. 7, n. 33, p. 238-252, 2017. Disponível em: http://www2.ifrn.edu.br/ojs/index.php/HOLOS/article/view/6093. Acesso em: fev 2020. DOI: https://doi.org/10.15628/holos.2017.6093

HABERMAS, J. Agir comunicativo e razão destranscendentalizada. Rio de Janeiro: Tempo Brasileiro, 2012.

KUENZER, A. Z. Ensino médio e profissional: as políticas do estado neoliberal. São Paulo: Cortez, 2000.

LIMA FILHO, D. L. L. O Proeja em construção: enfrentando desafios políticos e pedagógicos. Educação e Realidade, Porto Alegre, v. 35, n. 1, p. 109-127, jan./abr. 2010. Disponível em: https://seer.ufrgs.br/educacaoerealidade/article/view/11023. Acesso em: fev 2020.

MACHADO, M. M. A prática e a formação de professores na EJA: uma análise de dissertações e teses produzidas no período de 1986 a 1998. In: 23ª REUNIÃO ANUAL DA ASSOCIAÇÃO NACIONAL DE PÓS-GRADUAÇÃO E PESQUISA EM EDUCAÇÃO, 23., 2000, Caxambu. Anais[...] Caxambu: Anped, 2000.

MACHADO, M. M. Proeja: o significado socioeconômico e o desafio da construção de um currículo inovador. In: BRASIL. Ministério da Educação. EJA e a formação técnica integrada ao Ensino Médio: Boletim Salto para o Futuro. Brasília: MEC, 2006.

MORAIS, A. C. Prática pedagógica e formação dos professores da educação profissional na relação com concepções e princípios do Proeja. Orientadora: Maria Margarida Machado. 2015. 159 f. Dissertação (Mestrado em Educação) - Universidade Federal de Goiás, Goiânia, 2015. Disponível em: http://repositorio.bc.ufg.br/tede/handle/tede/5159. Acesso em: 27 fev. 2020.

MOURA, D. H. A formação de docentes para a educação profissional e tecnológica. In: BRASIL. Ministério da Educação. Revista Brasileira da Educação Profissional e Tecnológica. Brasília: MEC, v. 1, n. 1, p. 23-38, 2008a. Disponível em: http://www2.ifrn.edu.br/ojs/index.php/RBEPT/article/view/2863. Acesso em: fev 2020. DOI: https://doi.org/10.15628/rbept.2008.2863

MOURA, D. H. O Proeja e a formação de professores: desafios e avanços. In: CONGRESSO DE PESQUISA E INOVAÇÃO DA REDE NORTE NORDESTE DE EDUCAÇÃO TECNOLÓGICA, 3., 2008, Fortaleza. Anais[...] Fortaleza: Centro Federal de Educação Tecnológica, $2008 \mathrm{~b}$.

MOURA, D. H. O Proeja e a rede federal de educação profissional e tecnológica. In: BRASIL. Ministério da Educação. EJA e a formação técnica integrada ao Ensino Médio: Boletim Salto para o Futuro. Brasília: MEC, 2006. 
OLIVEIRA, E. C.; MACHADO, M. M. O desafio do Proeja como estratégia de formação de trabalhadores. In: OLIVEIRA, E. C.; PINTO, A. H.; FERREIRA, M. J. R. (Orgs.). EJA e educação profissional: desafios da pesquisa e da formação no Proeja. Brasília: Liber Livros, 2012.

PIMENTA, S. G; ANASTASIOU, L. G. Docência no Ensino Superior. São Paulo: Cortez, 2005.

RAMOS, M. N. Possibilidades e desafios na organização do currículo integrado. In: FRIGOTTO, G.; CIAVATTA, M.; RAMOS, M. (Orgs.). Ensino médio integrado: concepção e contradições. São Paulo: Cortez, 2012.

RIBEIRO, I. Especialização Proeja no IF-SC. Limites e possibilidades na formação de educadores. IFSC, Florianópolis, 2012.

SANTOS, T. A. De bacharel a professor: a construção dos saberes pedagógicos na educação profissional. Orientadora: Helena Farias de Barros. 2016. 106 f. Dissertação (Mestrado em Educação) - Universidade do Oeste Paulista, Presidente Prudente, 2016. Disponível em: http://bdtd.unoeste.br:8080/jspui/handle/jspui/967. Acesso em: jan. 2020.

SILVA, J. E. M. da. Estudo de caso avaliativo do currículo integrado do curso de refrigeração e climatização do PROEJA do IFCE. Orientadora: Meirecele Calíope Leitinho. 2013. 195 f. Tese (Doutorado em Educação) - Universidade Federal do Ceará, Fortaleza, 2013. Disponível em: http://www.repositorio.ufc.br/handle/riufc/6062. Acesso em: 27 fev 2020.

\section{Como referenciar este artigo}

SOARES, Sebastião Silva; DEVECHI, Catia Piccolo Viero. Política de formação docente no contexto do proeja: realidade e perspectivas. Revista Ibero-Americana de Estudos em Educação, Araraquara, v. 15, n. 2, p. 406-421, abr./jun. 2020. e-ISSN: 1982-5587. DOI: https://doi.org/10.21723/riaee.v15i2.12907

Submetido em: 10/03/2019

Revisões requeridas: 10/09/2019

Aprovado em: 16/11/2019

Publicado em: 20/02/2020 